\title{
UNA APRECIACIÓN RETÓRICA DE UN CLÁSICO SOCIOLÓGICO: EL SUICIDIO, DE DURKHEIM*
}

\author{
Michael A. Overington**
}

University of Halifax

\begin{abstract}
RESUMEN
Para ilustrar la aproximación retórica a los textos de las ciencias sociales, este trabajo aborda El Suicidio, de Durkheim, considerado en general como un modelo positivista, y lo lee como un discurso moral. La primera parte propone la iluminación que se proyecta sobre sus pautas de argumentación cuando la obra es abordada como una respuesta a una coyuntura moldeable por un discurso persuasivo. La última parte presenta el estatus clásico de la obra como resultado de su utilización como una autoridad retórica en orden a la legitimación de un cierto tipo de sociología.
\end{abstract}

* La preparación de este artículo se hizo con la ayuda del Social Science and Humanities Research Council of Canada, Leave Fellowship No. 451-801455, y con la amable hospitalidad de Ian Mangham y el Centre of Organizational Change and Development, Universidad de Bath. Se leyó una versión primera en la reunión anual de la Eastern Sociological Society, New York City, marzo de 1979. Jim Beam, Lloyd Bitzer, Joan Budge, Harold Goldblatt, Valerie Sloane y tres críticos anónimos han ayudado todos a mejorar este artículo. Desgraciadamente, como de costumbre, soy responsable de los errores restantes de «hecho" y de interpretación. Dirijan, por favor, toda comunicación o petición de reimpresión a Michael A. Overington, Department of Sociology, St. Mary's University Halifax, Nova Scotia.

** Canadian Journal of Sociology, 1981, 6 (4): 447-461. 


\section{INTRODUCCIÓN}

Hay un acuerdo general sobre la importancia de El Suicidio: estudio de sociología, de Durkheim, y numerosos sociólogos estarían de acuerdo con Whitney Pope: «la amplia aceptación de la sociología como una disciplina académica y científica se puede atribuir tal vez más a Durkheim que a ningún otro sociólogo, y El Suicidio es una fuente esencial de esa influencia» (1976: 202). En efecto, como «el clásico sociológico por excelencia» (La Capra, 1972: 177), su único competidor directo sería acaso La ética protestante y el espiritu del capitalismo (Weber, 1958). Sin embargo, de ningún modo hay un acuerdo tan grande respecto a cómo podríamos comprender ya sea el lugar de El Suicidio en el logro de respetabilidad académica para su sociología por parte de Durkheim, ya sea su importancia continua como una obra clásica. Uno puede preguntarse: ¿y qué interés tendría esto? Una respuesta, creo, se basa en la lectura de El Suicidio como una solución en su origen a una situación retórica que más tarde sirvió (como todos los clásicos) de emblema retórico para autorizar intereses específicos en la práctica sociológica. En otras palabras, El Suicidio (el gran clásico "positivista») ${ }^{1}$ puede entenderse mejor como un modelo de otra versión de la naturaleza de la ciencia social, una versión que comprende nuestra empresa como una forma de discurso moral que pretende crear un mundo (en vez de otro) por medio de una demostración persuasiva.

Es apenas necesario referirse una vez más a las dificultades que se encuentran en El Suicidio, ni se aborda como una perla de la ciencia positiva. Una reciente avalancha de trabajos analíticos ${ }^{2}$ ha indicado de diferente manera que sus datos estadísticos sobre el suicidio estaban en general disponibles en la investigación previa; que su teoría sobre el suicidio tiene grietas conceptualmente, cuando no es simplemente indemostrable; y, finalmente, que su teoría ni se sostiene ni está auténticamente probada, por lo menos en lo que podemos juzgar a partir de la propia presentación de Durkheim de los datos que la sostienen. Estos estudios ilustran la paradoja creada cuando se considera $E l$ Suicidio como un clásico fundador de la ciencia social "positiva». Los clásicos tienen un lugar en la sociología, pero sólo si apostamos por una noción de tal empresa que conciba el «conocimiento» de forma menos estricta que la evidenciada por los criterios positivistas. La contradicción estriba en la recomenda-

1 «Positivista» es un adjetivo aplicado casualmente que describe una colectividad de investigadores y de investigación lejos de estar unificada. Positivismo, positivismo lógico y neopositivismo han tenido éxito como empresas filosóficas sin imponer un uso del lenguaje cuidadoso (incluso para estas filosofías) en el discurso sociológico. Lo utilizo para referirme a un interés general por la explicación causal, el análisis multivariable y los datos cuantitativos que caracteriza ciertas tentativas sociológicas.

${ }^{2}$ Los trabajos generales más importantes son La Capra (1972), Lukes (1972) y Wallwork (1972). Podemos encontrar análisis extensos de El Suicidio en Pope (1976) y Douglas (1967: 3-76). Una multitud de artículos más cortos de interés para los especialistas se encontrará en las bibliografías de estos dos volúmenes. 
ción de esta obra como un ejemplo vital precisamente para esa clase de realizaciones científicas cuyos modelos la encontrarían seriamente defectuosa. Puesto que, a diferencia de las obras clásicas de Galileo o Priestley consideradas parte importante del "desarrollo» histórico del conocimiento científico, El Suicidio no es solamente alabado como un logro sociológico temprano, sino como un modelo para la emulación actual.

La mera paradoja, sin embargo, es menos interesante en sí misma que como una oportunidad de transformar nuestra manera de pensar la ciencia social a través de una consideración de la naturaleza retórica de El Suicidio. Me gustaría primero llevar a cabo una descripción de El Suicidio como una expresión retórica compleja que responde a elementos de la situación social e intelectual del tiempo y el lugar de Durkheim; y segundo, una reflexión sobre la utilización continuada de este libro como ilustración del carácter retórico de los clásicos sociológicos y de las posibilidades de la práctica sociológica para el análisis retórico.

No obstante, mi proposición no es la explicación más extensiva del texto de este libro, ni el análisis más amplio de las condiciones históricas y sociales que rodearon la institucionalización de la sociología en la academia francesa. Existen trabajos mucho mejores de universitarios competentes (por ejemplo: Clark, 1972: 152-186; 1973; Douglas, 1967: 3-76; La Capra, 1972; Lukes, 1972; Pope, 1976; Wallwork, 1972) que hacen superflua semejante tentativa. De hecho, este artículo trata tan accesoriamente de El Suicidio, de Durkheim, como este libro de los suicidios. El Suicidio, de Durkheim, utilizó un examen de la variación de las tasas de suicidio como vehículo para alegar la superioridad de su sociología a la hora de tratar los problemas morales asociados a un rápido cambio social. Sin embargo, a pesar de que quiero sostener que Durkheim eligió una cuestión que tendría una gran presencia retórica, también yo busco un efecto similar al tomar este libro de El Suicidio como tema. Como el proverbio de la pequeña pulga que contagia a la pulga mayor, me propongo basarme en ese libro con la intención de alegar la plausibilidad de las aproximaciones retóricas para comprender el discurso sociológico.

Ciertamente, este artículo no puede establecer la viabilidad de una aproximación retórica de la ciencia en general, o de la sociología en particular. Pero puede añadir un ángulo dramático a los muy prometedores ensayos ${ }^{3}$ que tanto

${ }^{3}$ La invención del análisis retórico de la ciencia no ha sido cosa fácil tras siglos de asumir que la retórica era el estudio del estilo literario y la oratoria clásica, y que la ciencia era una práctica instruida de manera lógica que determinaba lo que era verdadero o falso. Aun así, los últimos veinte años han visto grandes cambios en nuestra comprensión de la retórica y de la ciencia, de forma que podemos yuxtaponer ambos términos sin burla alguna. Se puede hallar una breve introducción de los cambios en nuestra comprensión de la ciencia, desde el punto de vista de la filosofía y de la historia, en Stephen Toulmin (1977: 143-162). La contribución de Suppé ofrece una descripción más larga y técnica en Suppé (1977). Para los sociólogos, numerosos resultados suscitados encuentran un contexto más familiar en Overington (1979: 2-12), y el intercambio que lo acompaña (1979: 12-34). Por otro lado, el desarrollo de la retórica de la ciencia ha sido lento y las más de las veces los trabajos han sido de carácter defensivo y preliminar. Entre los más 
han intentado alentar la investigación retórica de las ciencias como una nueva apertura con respecto a la comprensión de la «racionalidad natural» de la investigación sociológica y, más en general, científica ${ }^{4}$. El Suicidio ha sido tanto tiempo alabado como el logro principal de la ciencia positiva entre los sociólogos que cualquier esclarecimiento de esa obra en los términos del análisis retórico debe revelar algo inesperado y, por ende, interesante; por lo menos si hemos de creer, con Murray Davis, que «las teorías interesantes son aquellas que niegan ciertas suposiciones de su público...» (1971: 309)5.

\section{EL SUICIDIO Y SU MEDIO}

Durkheim hizo dos tentativas (la primera 1888: 446-463) para dar cuenta de la incidencia y de la variación de las tasas de suicidio. El Suicidio fue la segunda y vino después de unos cuantos años de docencia y de escritura como profesor de la universidad de Burdeos. Trabajó en esa universidad de 1887 a 1902, siendo nombrado para la primera cátedra de sociología en Francia en 1896. Su carrera universitaria culminó con su traslado a La Sorbona en 1902 y el nombramiento a la cátedra de Science de l'Education en 1906. Cuando el título de la cátedra se cambió por Science de l'Education et Sociologie se convierte en sólo la segunda cátedra de sociología en Francia. Sean los que fueran sus méritos académicos, el libro fue (junto con la revista académica, Année Sociologique, que Durkheim fundó en 1896) un vehículo para la difusión de la sociología durkheimiana en la universidad y en un medio intelectual más amplio.

Aunque numerosos detalles no son pertinentes aquí, la discusión fascinante de Terry Clark (1972) sobre el auge de los durkheimianos en las universidades francesas elabora algunos puntos importantes para nuestra comprensión del estatus retórico de El Suicidio. Tres factores son particularmente relevantes para esta comprensión:

importantes están Perelman y Olbrechts-Tyteca (1969) - la obra fundadora de la retórica de la ciencia, aunque restringida a las «ciencias humanas»-, Wander (1976: 226-235) y Leff (1978: 73-91). Una obra similar dirigida a las obras sociales se ilustra en Anderson (1978: 113-135), Overington (1977: 143-164), Philips (1973: 151-173), Weigert (1970: 111-119) y, finalmente, Weimer (1977: 1-29).

${ }^{4}$ S. B. Barnes (1976: 115-126) acuña la noción (que tiene fuertes lazos con la tradición del pragmatismo; ver Kaplan, 1964) como una manera de ofrecer el respeto debido a la práctica actual de los científicos sociales de modo que dejen abiertas, por lo menos, las cuestiones con respecto a la forma de su discurso. Overington (1979) lo comprende como una manera de pensar en cómo se crea el conocimiento sociológico a través de todas las imperfecciones de las relaciones humanas y del discurso persuasivo.

5 Desde luego, Maurice Halbwachs (1978) había señalado mucho antes como una cuestión importante, un problema interesante, "¿Era la dialéctica o las estadísticas la que aportaba la convicción?», pero fue olvidada generalmente hasta la traducción reciente de Harold Goldblatt. Ver también Huff (1975: 241-257). 
1. En la época en que El Suicidio se publicó había otros grupos de sociólogos en activo, fuera de la universidad, cuyos enfoques eran ajenos a Durkheim.

2. El espíritu cartesiano de la obra de Durkheim —moralidad basada en principios científicos - era en gran medida compatible con la opinión de importantes burócratas del Ministerio de Educación. Estas personas estaban impacientes por reformar la enseñanza superior francesa de manera que se inculcara a los jóvenes pedagogos un tipo de moralidad científica anticlerical. Más aún, este interés por reformar caracterizó la ascensión en la vida intelectual y pública de hombres como Durkheim, burócratas reclutados meritocráticamente y personas con inclinaciones académicas comprometidos racionalmente con una moralidad republicana.

3. La estructura profesoral y curricular de las universidades francesas en el fin de siècle era particularmente refractaria al cambio. Para hacerse un lugar, la sociología tuvo que ser lo bastante flexible para que sus seguidores encontraran plazas de filosofía y pedagogía en competición con filósofos, pedagogos y psicólogos.

Estos factores juntos constituyen lo que llamaré una situación retórica. Esto sigue la formulación germinal de Bitzer (1968), que presenta estas situaciones como ocasiones para transformar la realidad "gracias a la creación de un discurso que cambia la realidad a través de la mediación del pensamiento y de la acción» (1968: 4). A esta afirmación general sólo necesitamos añadir los tres componentes principales de tales situaciones — «exigencia», "público» y "constricción»-. En efecto, Bitzer concibe las situaciones retóricas como situaciones que contienen una exigencia — «algo que espera hacerse» (a través del discurso) - delante de un público que puede «ser constreñido en la decisión y la acción» —-dentro de constricciones que «influyen sobre el rétor y pueden llevar a influir sobre el público» (1968: 6).

Estos tres factores, extraídos de la explicación de Clark de la institucionalización de la sociología en las universidades francesas, revelan una perspectiva sobre la situación retórica en que se presentó El Suicidio. Me inclino a creer que lo que estaba "esperando hacerse», y era una exigencia de El Suicidio, tuvo que ver con el aumento de la aceptación de la sociología durkheimiana entre las élites concernidas con y acerca de la universidad. Sin embargo, creo que debería dejarse para una discusión posterior hasta qué punto la rigidez de las universidades francesas debería tratarse como una audiencia o una constricción, los grupos de sociólogos competidores han de ser considerados como audiencia o constricción, y así sucesivamente. No es mi intención, por tanto, dividir estos tres factores entre exigencia, audiencia y constricciones, a pesar de la apariencia de sencillez de tal disposición. Mi preferencia es, más bien, algo menos definida que esto y sugiere que el texto de El Suicidio puede tratarse como un discurso que "habla" a diversos elementos en estos factores sociales e intelectuales. Por lo tanto, el efecto de El Suicidio puede considerarse realizado 
gracias a la habilidad retórica con la que Durkheim argumenta en un contexto social e histórico particular que se transforma en una situación retórica por sus brillantes técnicas de persuasión.

No obstante, leer textos (retóricamente o de otro modo) es un asunto difícil y debemos ser cuidadosos al distinguir entre las interpretaciones que, de diversa manera, dependen de las intenciones de los autores, de las respuestas del público y de los textos mismos. Mi interpretación aquí depende de la lectura de El Suicidio en el contexto de una breve descripción de los públicos importantes contemporáneos del libro. Cuento con que el texto mismo y el concepto de persona $a^{6}$ - la "voz" accesible en los textos independiente de todo conocimiento de los autores o de sus intenciones - sirvan de protección contra el sofisma post ergo propter hoc. La plausibilidad de esta lectura, sin embargo, sólo puede depender de la buena voluntad de mi público para considerar conmigo este libro como una respuesta a una situación retórica.

\section{SITUACIONES RETÓRICAS: EL SUICIDIO COMO RESPUESTA}

En mi opinión, El Suicidio es en realidad dos libros: un estudio empírico de las tasas de suicidio en el siglo XIX en Europa, y un intento sensible y moralmente interesado de utilizar las tasas de suicidio como indicadores de los efectos del cambio social drástico en la construcción de la sociedad. Sus cuestiones más importantes son entonces «¿qué efectos tienen los cambios sociales importantes en las tasas de suicidios?» y "¿qué dicen estos cambios sobre la salud moral de la sociedad?». En un sentido, como indiqué anteriormente, el libro sólo trata accesoriamente del suicidio. Como obra, El Suicidio se aventura en una aproximación sociológica a lo que en general se considera un acto individual, pero para demostrar algunas de las consecuencias morales de la ruptura en la integración comunitaria. La obra puede así no sólo revelar qué es sociológico, sino también que esta sociología puede tratar un problema individual (la competencia tradicional de la psicología) que tiene profundas dimensiones morales (la guarda usual de la filosofía).

Al comienzo de El Suicidio, en el prefacio, la persona de Durkheim bosqueja brevemente su idea de la sociología y las razones para este estudio particular. Ahí, distingue de forma inequívoca su sociología de los estudios de «sociología pura» con sus «brillantes generalidades» que sólo ofrecen «ilustraciones» por

" Para evitar la torpeza de decir la «persona de El Suicidio», o la "persona de Durkheim», cada vez que es necesario he usado expresiones tales como "Durkheim presenta", "Durkheim subraya», o "él» como si hiciera referencia al mismo Durkheim, a sus intenciones y no a la voz utilizada en este libro. Sin embargo, quisiera que los lectores entiendan que sólo estoy hablando de la persona del libro y que no tengo intención de hablar de las intenciones de Durkheim. El concepto de persona se refiere a la voz del autor como puede comprenderse en un texto. Como elementos de textos, personae pueden ser tratadas en un análisis retórico sin presuposiciones de conocimiento de autores o de sus intenciones. 
prueba. Sostiene que se emprende el estudio del suicidio porque el tema está suficientemente delimitado y bien definido (así como "particularmente oportuno»), de manera que "pueden descubrirse leyes reales que demuestren la posibilidad de la sociología mejor que cualquier argumento dialéctico» (1951: 37).

Continúa así sugiriendo que El Suicidio es, de hecho, un ejemplo concreto de los principios y problemas de los métodos sociológicos que ya había tratado previamente en Las reglas del método sociológico. Con ese juicioso anuncio de una obra que sirvió de Biblia metodológica a los durkheimianos (Clark, 1972: 168) prosigue con su énfasis característico: «el método sociológico tal como lo practicamos reposa totalmente en el principio básico de que los hechos sociales deben ser estudiados como cosas, eso es, como realidades externas al individuo. No hay un principio por el que hayamos recibido más críticas; pero ninguno es tan fundamental» $(1951: 37-38)^{7}$. En realidad, la noción de hechos sociales comme des choses se convirtió en el eslogan durkheimiano.

Así, al principio de la obra, Durkheim declara que su sociología es distinta de las otras, y su carácter distintivo se basa en un nuevo orden de realidades sociales que trascienden los factores individuales: «emergerá de cada página de este libro, por decirlo así, la impresión que el individuo está dominado por una realidad moral mayor que él: a saber, la realidad colectiva» (1951: 38). La sociología, por tanto, tiene un área propia de competencia intelectual que no debe considerarse como una intrusión en las disciplinas académicas establecidas. Esto era acertado, dada la influencia limitada de Durkheim en el sistema universitario. Con todo, al mismo tiempo, está dispuesto a afirmar que su sociología puede tratar de materias relativas a la moral y al individuo, ¡los temas de la filosofía y la psicología!

Esta audaz afirmación le permite apelar a un público de personas orientadas hacia el individualismo de las aproximaciones filosóficas y psicológicas convencionales de la conducta humana (y eso incluiría seguramente a los miembros de la intelectualidad y la burocracia de la educación) sin pisotear torpemente las prerrogativas académicas de estas disciplinas. Sin embargo, para tener éxito en esta tentativa, debe establecer que el suicidio puede considerarse un hecho social, no individual, y que las realidades sociales que producen el suicidio son significativas en términos individuales. ¡No pequeña empresa! Logra esto en pocas líneas. Primero, define el suicidio como un fenómeno colectivo; segundo, elimina con sus argumentaciones "todas» las explicaciones de este fenómeno excepto la suya; tercero, revela que las fluctuaciones de las tasas de suicidio responden a factores colectivos; y, finalmente, presenta hábilmente las imágenes del estado mental de los individuos en los diversos tipos de suicidio. Veamos algunas de estas realizaciones.

$\mathrm{Al}$ conseguir con esfuerzo una definición del suicidio, Durkheim reconoce su carácter individual: "ya que el suicidio es una acción individual que afecta sólo al individuo, aparentemente debe depender exclusivamente de factores

7 Sólo más tarde encontraremos la lucha de Durkheim con Marx; ver Llobera (1978). 
individuales, y pertenecer así sólo a la psicología» (1951: 46). Por lo tanto, debe especificar que no se interesa por el suicidio, sino por las tasas de suicidio, que concibe como «un orden objetivo, unificado y definido, como lo muestran su permanencia y su variabilidad» (1951: 51). Es decir, que estas tasas no son meramente la suma de sus componentes individuales, sino que representan una tendencia colectiva de la sociedad que fluye como una corriente eléctrica, encontrando mayor o menor resistencia, como lo ponen de relieve los actos individuales de suicidio.

Al establecer las tasas de suicidio, su permanencia y variación, como sus explanada, Durkheim procede a examinar una variedad de explicaciones posibles que han sido propuestas por otros que han escrito sobre el suicidio. En esta sección del libro compite con las explicaciones alternativas que pudieran influir sobre su público para que rechace su propia posición. Como un recién llegado en este campo, trata primero de éstas, antes de llegar a su propia descripción. Cada alternativa (raza, clima, locura, etc.) se expone plausiblemente y es entonces cuidadosamente rechazada como inadecuada de diversas maneras a causa de las dificultades estadísticas, conceptuales o lógicas que crea.

Con respecto a la variación del suicidio según las estaciones, por ejemplo, leemos acerca de los efectos del calor excesivo en un texto muy expresivo que describe marineros en garras de tales «horrores» que "los que son sus presas son impulsados irresistiblemente a lanzarse al agua, sea vencidos por el vértigo en medio del trabajo en los mástiles, sea durante el sueño, del que despiertan violentamente con gritos aterradores» (1951: 110). Casi inmediatamente, sin embargo, ofrece datos estadísticos para argumentar que no existe una relación simple entre los extremos climáticos, ya sea el frío o el calor, sino más bien una «ley» que describe la relación del suicidio con los cambios de estación de forma que las tasas aumentan de enero a junio y después descienden hasta el final del año. Esto lleva a la afirmación de que la regularidad de estos aumentos y descensos sólo puede estar causada por algún factor que varíe con la misma regularidad; las causas y los efectos son semejantes. Existe, como pone en evidencia, un paralelo perfecto entre la variación de la duración de la luz del día y la tasa de suicidio - la tasa del cambio de las horas de luz varía simultáneamente con el cambio en las tasas de suicidio-. Pero ¿cómo puede la luz del día producir suicidios? No directamente, como resultado de la luz del sol o de la temperatura, sino porque "el día (...) es el tiempo de la existencia más activa, cuando las relaciones humanas se cruzan y se vuelven a cruzar, cuando la vida social es más intensa" (1951: 117). El suicidio se relaciona con la actividad social intensa: cuanto más dispone de luz y de temperatura la actividad social, más crece la tasa de suicidio, y viceversa. Y así cerramos el círculo de los cambios de estación y del clima como explicaciones de las variaciones de la tasa de suicidio; esta vez no como explicaciones en sí mismos sino como indicadores engañosos de las variaciones de intensidad de la vida social. Además, tiene especial cuidado en sostener que, aunque alguna de estas alternativas ofrezca alguna comprensión de los suicidios individuales, no tienen nada que decir en 
relación con las tasas de suicidio. Por ejemplo, concluye de la noción de «imitación» de Gabriel Tarde (y Tarde era un rival intelectual, cuya estrella brillaba para esas fuerzas opuestas al espíritu cartesiano de los burócratas reformadores de la universidad; Clark, 1972: 172-173) que «tan cierto como que el contagio del suicidio va de individuo a individuo, la imitación nunca parece propagarlo de manera que afecte a la tasa social de suicidio" (1951: 140).

Este modelo de argumentación se repite a menudo. Primero, se traza una explicación particular del suicidio, siendo presentada e ilustrada con algún esfuerzo para hacerla creíble. Entonces sigue una investigación de las consecuencias que tendría esto, contrastada con estadísticas e ideas de sentido común. Esta argumentación se completa cuando los modelos de relación existente entre raza, clima, cambios de estación y similares se exponen para ser explicados como simples indicadores que no son más que emblemas de las causas sociales reales de la fluctuación de las tasas de suicidio. El efecto de esto, al repetirse, es despertar un sentido anticipador de la importancia y la veracidad de esta nueva noción —dándole una presencia retórica según los lectores avanzan hacia la presentación final de la teoría del suicidio como fenómeno colectivo.

Tras haber invalidado las explicaciones alternativas del suicidio más verosímiles, familiares y plausibles para su público, llega la tarea principal de este libro - un despliegue de las causas sociales de la fluctuación de las tasas de suicidio-. La familiaridad general con su análisis de los tipos de suicidio egoísta, anómico y altruista, producto de la variación de los niveles de integración y de regulación, hace superfluo que nos detengamos en ello. Para comprender la habilidad retórica exhibida en El Suicidio, es más importante considerar las técnicas empleadas para asegurar que un público orientado hacia explicaciones individualistas y no familiarizado, cuando no abiertamente hostil, con las «realidades colectivas» atendiera a la aproximación colectiva de Durkheim. Después de todo, los pensadores de lo colectivo de principios del siglo XIX en Francia, como DeMaistre y Bonald, habían sido conservadores reaccionarios opuestos al individualismo republicano de los burócratas de la educación que Durkheim quería conquistar para su sociología. Al proponer una realidad colectiva como nivel de análisis separado, se hallaba en terreno peligroso.

En El Suicidio se emplean dos técnicas principales para individualizar estas realidades sociales. La primera de éstas —el tratamiento de la sociedad como si fuera un individuo- es conocida a raíz de las críticas convencionales del enfoque de Durkheim. Esta descripción de la sociedad como un miembro individual de la clase de todas las sociedades nunca se hace explícita y opera como una de las claves, de las premisas no mencionadas de la argumentación de $E l$ Suicidio. Podemos detectar esta premisa en numerosos pasajes que presentan la sociedad como un individuo. Encontramos, por ejemplo: «cuando la sociedad está fuertemente integrada, tiene a los individuos bajo control, los considera a su servicio y les prohíbe disponer libremente de sí mismos. Así pues, se opone a que se evadan de sus deberes para con ella por medio de la muerte» (1951: 209). El lector ocasional de El Suicidio no tendría ninguna dificultad en pro- 
porcionar docenas de ejemplos similares. Pero, al dar a la sociedad una personalidad, necesidades, deseos, propósitos y demás, no sólo está reificándola (después de todo, su propio dictado metodológico era tratar los hechos sociales comme des choses), sino que también permite que el carácter extraño del nivel colectivo de análisis se deslice en términos familiares, individualistas.

La segunda de estas técnicas es menos familiar y rara vez objeto de crítica. En la sección principal del libro, que trata de los tipos de suicidio como polaridades de una línea continua, da a su público imágenes evocadoras de los estados mentales individuales de los suicidios egoísta, anómico y altruista (para los que, por supuesto, no tiene datos estadísticos), y concluye con un capítulo entero que ilustra el carácter individual de sus tipos de suicidio. Nada de esto sería raro si no fuera por el énfasis de Durkheim en los datos estadísticos y en las tasas de suicidio que le exime de dar información sobre los individuos. Apenas podemos comprender esta clase de datos en términos de lo que él propondría para los métodos científicos. En realidad, tuvo el buen talante de advertir, a propósito del capítulo sobre los tipos individuales de suicidio, que aunque se trata «sólo de un método de ilustrar los resultados precedentes con ejemplos, habría merecido la pena dar un carácter más concreto al conectarlos (...) con la experiencia diaria» (1951: 278). Sin embargo, no sería menos viable dar cuenta de su uso, si tratáramos esas ilustraciones, tanto las conocidas como las solamente deslizadas entre las cifras, como recursos retóricos para comunicar con un público acostumbrado a explicaciones individualistas de los estados individuales.

Tomemos, por ejemplo, la vivaz evocación de Durkheim de la situación anómica en condiciones de progreso en la esfera económica:

«De arriba a abajo de la escala, la ambición se despierta sin saber dónde encontrar el apoyo definitivo. Nada puede calmarla, cuando su meta está mucho más allá de su alcance. La realidad parece desvalorizada en comparación con los sueños y la imaginación febril (...) Surge una sed de novedades, placeres desconocidos, sensaciones sin nombre, que pierden su sabor una vez conocidos. A partir de entonces se carece de fuerza para soportar el menor revés...» (1951: 256).

Ésta es una ilustración retórica sumamente afortunada, un extracto de El Suicido de los más citados hasta hoy (y eso es de por sí una situación interesante). Con todo, se ha deslizado como una descripción del estado crónico de anomia sin el beneficio de una explicación de su origen, estatus, o una prueba que lo verifique.

De la misma manera, Durkheim se apoya en una serie de autoridades literarias: Lamartine, Chateaubriand, algunos documentos personales presentados por Bierre de Boismont - y éstos fueron rechazados al principio del libro como «insuficientemente objetivos» (1951: 146)_, etc., que dan un "carácter concreto" a los tipos de suicidio en su forma individual. Por ejemplo, en el 
Raphael de Lamartine se nos muestra el tipo ideal del carácter egoísta que describe su estado mental como languidez melancólica: "una enfermedad humana, pero una cuya experiencia no provoca sino dolores, y en la que la muerte se asemeja a una caída voluptuosa en el infinito» (1951: 280). Haciendo esto, espera «seguir las diversas corrientes que generan el suicidio de sus orígenes sociales hasta sus manifestaciones individuales» (1951: 277). Está claro que su procedimiento de prueba aquí sería mucho más familiar para un público que ignoraba en general las formas del razonamiento estadístico empleadas en otra parte del libro. Podemos recordar con ironía las grandes ambiciones metodológicas que Durkheim propone al comienzo de El Suicidio (que he presentado al principio de este artículo), cuando distingue $s u$ sociología de las otras aproximaciones que sólo ofrecían «ilustraciones» por prueba y «generalidades brillantes» por conclusiones. Con todo, ilustraciones que son, en el mejor de los casos, equívocas al desarrollar «leyes reales (...) que demuestran la posibilidad de la sociología mejor que cualquier argumento dialéctico» (1951: 37) pueden, no obstante, servir muy bien como técnicas retóricas al crear un público para la sociología de Durkheim.

Al comienzo de este análisis sugerí que al leer El Suicidio podemos encontrar los esfuerzos retóricos de Durkheim para defender los méritos de su sociología como únicamente interesada en un nivel social de realidad. Vimos entonces un número de técnicas que se emplean para ayudar a que el público (burócratas de la educación e intelectuales) encuentre plausible tal defensa. Debemos volver ahora sobre el último elemento importante de El Suicidio —su interés por las consecuencias del cambio social-, que "habla» a un público que desea una moral científica, que pueda ser enseñada a los futuros profesores de secundaria y, por tanto, transmitida a sus alumnos.

La verdadera naturaleza de la conceptualización de las fluctuaciones de las tasas de suicido por parte de Durkheim, como indicadores de profundos trastornos en la integración moral de las sociedades y de los grupos específicos en su interior, muestra una sensibilidad retórica. El problema principal con el que se enfrenta la sociedad contemporánea, en opinión de Durkheim, es el aislamiento de los individuos respecto de la implicación en la vida significativa del grupo; los suicidios anómico y egoísta resultan de esto. Sólo gracias a la propia implicación en la vida social se vuelven los individuos sensibles a la moral social que moldea esa vida de manera colectivamente aceptable. Si los grupos sociales se quiebran, si las personas no se implican lo bastante en ellos, la estabilidad moral de una sociedad queda comprometida y los individuos quedan sin protección frente a las corrientes suicidógenas que barren la sociedad y «arrasan» a quienes no están a resguardo gracias a sus relaciones sociales.

Para Durkheim, no hay vuelta à l'ancien régime en busca de una vida comunitaria moralmente envolvente. El presente es el mundo de un estado centralizado donde «nada hace que las personas salgan de sí mismas ni les impone un freno. Así caen inevitablemente en el egoísmo o la anarquía» (1951: 389). Los grandes disturbios de la Revolución dieron lugar a una socie- 
dad unificada y centralizada con lealtad a la nación, pero sin regulación moral suficiente. Debe desarrollarse, sostiene Durkheim, alguna organización comunal que se alce entre el individuo y el Estado para implicar a las personas en una vida regulada moralmente y restaurar la estabilidad. Su juicio es que la mejor de tales organizaciones sería de carácter ocupacional — respondería a la implicación funcional principal de los individuos en la sociedad sin destrozar el importante efecto unificador de una relación directa de los individuos con el Estado.

Si esta proposición particular era realista o no es de poco interés. Lo que habría tenido más importancia para la audiencia que buscaba era la voluntad de abordar una cuestión moral con técnicas "científicas», y hacer recomendaciones para tratar problemas aprobados científicamente. La concepción de Durkheim de la sociedad como una colectividad moral que requiere que los individuos se impliquen de manera apropiada y estén controlados por sus prójimos dio una justificación científica a la moral secular. En un sentido, su noción de la implicación apropiada y de la regulación no era sino una versión moderna de la interpretación de Aristóteles de la virtud moral que sigue un curso moderado entre extremos. Durkheim, sin embargo, fue capaz de argumentar que la desviación de un término medio hacia los extremos del egoísmo y del altruismo, de la anomia y del fatalismo, tenía consecuencias medibles en las fluctuaciones de las tasas de suicidio. Así podía establecerse científicamente la virtud moral y, en realidad, justificarse la lealtad republicana al Estado.

En este punto, he sostenido que podemos comprender el logro y el éxito de El Suicidio, de Emile Durkheim, en términos de argumentación persuasiva como una intervención retórica en una situación que era maleable. En el libro, en contraste con cualquier competición, Durkheim revela el carácter único de su enfoque sociológico. Las realidades colectivas que constituye en factores causales son muy nuevas y, por tanto, no presentan influencias directas de otras disciplinas académicas. No obstante, aunque no represente una amenaza directa para el orden académico establecido, es capaz de demostrar la eficacia de su análisis cara a la explicación del suicidio, un fenómeno considerado como un problema moral de los individuos, por lo tanto dentro del ámbito competencial de las disciplinas científicas tradicionales. Fue, sin duda, un coup de main retórico. La reputación histórica muestra el éxito de los durkheimianos al establecerse como la escuela de sociología en las universidades francesas ${ }^{8}$. Con independencia de otras maniobras que ese éxito requiriera, puedo sostener que la hábil forma retórica de El Suicidio le dio, en su inicio, una credibilidad sorprendente que le permitió desempeñar un papel importante como modelo de su aproximación.

${ }^{8}$ La importancia de esta escuela tiene ahora mismo mucho interés para los sociólogos, como lo indica la fundación reciente de un grupo de investigación, Le group d'études durkheimiens, y las publicaciones de Clark (1973) y Nandan (1977). 


\section{EL SUICIDIO COMO UNA «AUTORIDAD» MODERNA}

Al pasar de una consideración del carácter retórico ejemplar de El Suicidio para los durkheimianos a la presente descripción del libro por parte de Merton (en palabras de Robert Biersted) como «una de las más importantes obras de investigación sociológica jamás realizadas» (1968: 63), quiero fijar la atención de nuevo en sus características como modelo sociológico. Una vez más, mis intereses no se fijan concretamente en El Suicidio, sino de manera más vaga, en cómo podemos pensar la continua "presencia» (por ejemplo, ver Karon, 1976) de este libro en nuestro discurso como una ilustración adicional de la aplicación del análisis retórico a las ciencias sociales.

El Suicidio es un clásico sociológico. Ningún manual, historia de la teoría sociológica o introducción selectiva a las obras maestras de la sociología estaría completo sin al menos una mención del libro. A pesar de las críticas de su uso de la teoría, elección de métodos de análisis y selección de datos, la obra perdura como un todo. Merton proporciona algunas funciones para el empleo continuado de los clásicos sociológicos: «éstos van desde el placer directo de (...) una versión estéticamente grata y más convincente de nuestras propias ideas (...), la satisfacción de la confirmación independiente de estas ideas (...), la función educativa de desarrollar elevadas normas de gusto cara al trabajo sociológico hasta (...) el desarrollo de nuevas ideas al releer los antiguos escritos en el contexto del conocimiento contemporáneo» (1968: 37-38). Sin embargo, no se consigna claramente el empleo del libro como un modelo retórico. Cualquiera que fuera el éxito que este libro pudo haber tenido en la época de su primera publicación, su importancia continua es un hecho contemporáneo que depende, sólo en parte, de ese temprano triunfo. Es decir, que es sólo la representación de ese temprano éxito por parte de los escritores contemporáneos la que ofrece algunas razones fundamentales del estatus clásico del libro. La cuestión entonces es: ¿cómo sirve El Suicidio hoy de modelo? La respuesta es triple: proporciona una ilustración concreta de lo que interesa a la sociología (populariza); de cómo se realiza la investigación sociológica (inicia); y de qué representan los sociólogos (celebra).

Thomas Kuhn (1970: 163-166) y, antes que él, C. Wright Mills (1963: 525-552) han sostenido que los manuales (y seguramente las recopilaciones de textos) son dispositivos para comunicar el «paradigma» o la «ideología» de muchos grupos científicos. Siguiendo a Perelman y Olbrechts-Tyteca (1969), podemos considerar las dimensiones retóricas de la comunicación de los manuales como dotadas de dos caras. Los manuales presentan una popularización de la historia, valores y conocimiento de algunas disciplinas, y comienzan la iniciación de miembros potenciales del público disciplinario. La popularización es una forma de comunicación que simplemente pone algún público al tanto de los valores aceptados y del conocimiento del área científica. Por otro lado, la iniciación "consiste en comunicar (...) reglas, técnicas, ideas específicas, y presupuestos, tanto como el método de criticar los resultados en térmi- 
nos de los propios requisitos de la disciplina» (1969: 100). Por supuesto, antes de poder iniciar personas a un público científico, se necesita persuadirles de que valdría la pena. En este contexto «ideológico» propondría situar el estatus de El Suicidio como un modelo - como una autoridad que diversos autores pueden señalar cuando describen una tradición de trabajo valioso y distinguido en sociología.

El Suicidio puede usarse para dar ejemplo del interés del sociólogo por tratar la "gran» cuestión que atormenta al mundo social. En el concepto de Durkheim de anomia — un sentido del desarraigo que podría inducir al suicidiopodemos encontrar la descripción del malestar de los tiempos modernos y la condición de los seres humanos en un mundo de creciente especialización y diferenciación (Hammond et al., 1975: 390-391). Por deducción, entonces, podemos afirmar que El Suicidio es el comienzo (con otras obras clásicas) de una tradición de preocupación sociológica por cuestiones importantes, como el estado del mundo moderno, así como forma parte del interés fundacional de la sociología en los problemas sociales.

Otra dimensión del carácter ejemplar de El Suicidio vuelve a su éxito original al establecer la realidad colectiva como el único nivel del análisis sociológico. "Fue el gran mérito de Durkheim como teórico sociológico ver e insistir en el carácter distinto de la explicación sociológica, en contraste con la psicológica» (Rex, 1970: 6). A través del trabajo de Durkheim en El Suicidio podemos sugerir que el carácter único de nuestro nivel de análisis tiene el mismo estatus que la psicología, el competidor más importante por los «corazones y mentes» de los estudiantes en ciencias sociales (De Fleur et al., 1976: 9). Con independencia de que algún fenómeno parezca explicarse completamente en términos personales, El Suicidio es capaz de demostrar que hay niveles de causalidad que resultan invisibles si se consideran los individuos uno por uno. Así, podemos sugerir que no todo es como le resulta al sentido común, a la persona no iniciada; hay niveles de realidad que son revelados por los análisis sociológicos a aquellos entrenados en su utilización.

Tal vez la dimensión última de El Suicidio, empleado como un modelo, es precisamente una forma del análisis sociológico. En palabras de Robert Nisbet, se trata de "una explicación que a grandes rasgos puede aceptarse todavía hoy como el modelo de lo que una explicación científica sería en sociología» (Nisbet y Perrin, 1977: 14-15; Zelditch, 1979: 52-55). Podemos encontrar numerosas razones dadas de esta elección del libro como modelo de explicación. El trabajo de Durkheim fue cuidadoso y esmerado, fue una utilización innovadora de las estadísticas sociales, una aplicación de datos estadísticos a un problema individual, etc. Sean cuales fueran las razones, las técnicas más bien toscas de El Suicidio (en comparación con los métodos más refinados que empleamos hoy) establecieron, sin embargo, una base científica para la disciplina.

En efecto, entonces, semejante representación de El Suicidio da pie para que lo que algunos sociólogos aceptan como "virtudes» sean releídas en un texto fundacional $(U r$-text), de vuelta a los innegables cimientos de la discipli- 
na. Por lo tanto, a pesar de sus defectos, El Suicidio puede presentarse como una autoridad fundadora para semejante visión de la sociología. Como un modelo de este tiempo (otros períodos pudieran encontrar diferentes elementos que requieran más presencia retórica), El Suicidio ilumina el interés de la sociología por el estudio de los problemas sociales, que están de algún modo ligados a las cuestiones sociales más importantes, por medio de técnicas científicas de investigación (en gran medida estadísticas) que investigan y revelan una realidad social escondida.

Zelditch (1979) acierta con respecto de los tipos de utilización que según mi propuesta caracterizan las referencias de los manuales contemporáneos a $\mathrm{El}$ Suicidio - justifican nuestra atención a ciertos tipos de principios y, por tanto, fomentan la construcción de estilos sociológicos específicos- Sin embargo, un análisis retórico adquiere un interés ex post facto. Así, con independencia de las influencias que operen en el desarrollo de métodos sociológicos particulares (y no hemos intentado tratar de éstos), una preocupación retórica anticiparía que tras tales desarrollos habría que esforzarse en darles algún título de autoridad, atraer adeptos, situarlos en el marco de las realizaciones más ampliamente aceptadas en la disciplina. El Suicidio, entonces, ha sido empleado al modo de la más antigua de las persuasiones históricas, el argumentum ad auctoritatem. La mayoría de nosotros ha concebido tal argumento como una forma de sofisma lógico; su redescubrimiento tiene mucho que decir sobre el carácter retórico de la práctica sociológica.

\section{CONCLUSIÓN}

¿Qué se aprende aquí? Ciertamente, nada definitivo; en realidad, la forma ensayística en la que presentamos nuestra propuesta es poco dada a la evidencia robusta y las conclusiones firmes. No obstante, pienso que ofrece dos propuestas. Primero, es claro que puede funcionar una aproximación retórica de El Suicidio en tanto que respuesta a la situación en que Durkheim presentó el libro. El libro puede entenderse como un sutil discurso retórico bien ejecutado para un público crítico, que tuvo éxito al ofrecer un modelo persuasivo de la sociología durkheimiana. Segundo, a pesar de las críticas impresionantes y bien conocidas, la influencia continua de El Suicidio en la sociología contemporánea tiene bases sólidas. El libro opera como una autoridad clásica que privilegia (mediante apelaciones retóricas) intereses específicos y prácticas de investigación en sociología. En otras palabras, si fuéramos a formular la sociología como una empresa retórica, como algo interesado en el modo en que el discurso persuasivo desemboca en conclusiones moralmente informadas y defendibles racionalmente sobre el mundo social, El Suicidio (más generalmente pensado para autorizar una opinión muy diferente) pudiera bien estar de nuestro lado.

Sin embargo, El Suicidio no es el único que puede utilizarse así. Desde una 
perspectiva retórica, lo que convierte en «clásica» a una obra es su utilización continua como autoridad para las prácticas más recientes. Si tomamos cualquier publicación general de nuestro campo, vemos desfilar a Weber, Marx, Simmel y muchos otros, como textos y personajes para autorizar argumentos. Los clásicos sociológicos adquieren ese estatus como autoridades post hoc para la práctica contemporánea: se convierten en clásicos gracias a su utilización como autoridades. Mientras que una pequeña empresa florece en la reclamación de semejantes autoridades para una utilización posible en nuestras persuasiones, sólo algunas reclamaciones tienen éxito. Esto será un puzzle continuo hasta que adoptemos las propuestas que proporciona el análisis retórico: toda aclaración ofrecida por este examen de El Suicidio sólo puede ser un comienzo en esa dirección.

Con todo, es seguro que tal era el propósito reconocido del artículo - fomentar la credibilidad del análisis retórico mediante el examen de El Suicidio_- Existe una discusión creciente sobre nuestra autocomprensión (para una introducción, ver Overington, 1979, y el intercambio adjunto), sobre cómo podemos entender los razonamientos y contextos en que se constituye el conocimiento sociológico. La investigación retórica sólo es una estrategia posible para distinguir nuestra práctica de las prescripciones reconstruidas para esa práctica que han dejado de ser vitales filosóficamente (perecen bajo el peso de sus propios problemas), o útiles pragmáticamente (pocos los emplean en su práctica). Con todo, un análisis retórico de El Suicidio como modelo retórico no puede ser más que un modelo retórico de un análisis retórico.

\section{BIBLIOGRAFÍA}

ANDERSON, D. (1978): «Some organizational features in the local production of a plausible text", Philosophy of the Social Sciences, 8: 113-135.

BARNeS, S. B. (1976): "Natural rationality: a neglected concept in the social sciences», Philosophy of the Social Sciences, 6: 115-126.

BitZer, Ll. F. (1968): «The rhetorical situation», Philosophy and Rhetoric, 1: 1-14.

Clark, T. N. (1972): «Emile Durkheim and the French university», en A. Oberschall (ed.), The Establishment of Empirical Sociology, Nueva York: Harper and Row, pp. 152-186.

- (1973): Prophets and Patrons, Chicago: University of Chicago Press.

Davis, M. (1971): «That's interesting», Philosophy of the Social Sciences, 1: 309-344.

De Fleur, M., et al. (1976): Sociology: Human Society, Glenview, Illinois: Scot, Foresman.

Douglas, J. D. (1967): The Social Meanings of Suicide, Princeton, Nueva Jersey: Princeton University Press.

DurkheIm, E. (1888): «Suicide et natalité: étude de statistique morale», Revue philosophique de la France et de l'étranger, 26: 446-463.

- (1938): The Rules of Sociological Method, Nueva York: The Free Press (1895: Les règles de la méthode sociologique, París: Alcan).

- (1951): Suicide: A Study in Sociology, Nueva York: The Free Press (1897: Le suicide: étude de sociologie, París: Alcan).

HalbwaCHS, M. (1978): The Causes of Suicide, Translated by Harold Goldblatt, Nueva York: The Free Press. 
Hammond, Ph., et al. (1975): The Structure of Human Society, Lexington, Massachusetts: D. C. Heath.

Huff, T. (1975): «Discovery and exploration in sociology. Durkheim's Suicide», Philosophy of the Social Sciences, 5: 241-257.

Kaplan, A. (1964): The Conduct of Inquiry, Scranton, Pennsylvania: Chandler.

Karon, L. (1976): "Presence in The New Rhetoric», Philosophy and Rhetoric, 9: 96-111.

Kunn, T. (1970): The Structure of Scientific Revolution, Chicago, University of Chicago Press.

La Capra, D. (1972): Emile Durkheim: Sociologist and Philosopher, Ithaca, Nueva York: Cornell University Press.

LuKES, S. (1972): Emile Durkheim: His Life and Work, New York: Harper and Row.

LEFF, M. (1978): «In search of Ariadne's thread: a review of the recent literature in rhetorical theory», Central States Speech Journal, 29: 73-91.

Llobera, J. (1978) «Durkheim, the Durkheimians and their collective misrepresentation of Marx», Durkheim Session, 9th World Congress of Sociology, Upsala.

Merton, R. (1968): Social Theory and Social Structure, Nueva York: The Free Press.

Mills, C. W. (1963): Power, Politics and People, Nueva York: Oxford University Press.

NANDAN, Y. (1977): The Durkheimian School: A Systematic and Comprehensive Bibliography, Westport, Connecticut: Greenwood Press.

Nisbet, R., y Perrin, R. (1977): The Social Bond, Nueva York: Alfred Knopf.

Overington, M. A. (1977): "The scientific community as audience: toward a rhetorical analysis of science», Philosophy and Rhetoric, 10: 143-164.

- (1979): «Doing the what comes naturally: some developments in metatheory», The American Sociologist, 14: 2-12.

Perelman, Ch., y Olbrechts-Tyteca, L. (1969): The New Rhetoric: A Treatise on Argumentation, Notre Dame, Indiana: University of Notre Dame Press.

PHILlips, D. (1973): Abandoning Method, San Francisco: Jossey Bass.

Pope, W. (1976): Durkheim's Suicide: A Classic Analyzed, Chicago: University of Chicago Press.

ReX, J. (1970): Key Problems of Sociological Theory, Nueva York: Humanities Press.

Suppe, F. (ed.) (1977): The Structure of Scientific Theory, Urbana: University of Illinois Press.

Toulmin, S. (1977): «From form to function: philosophy and history of science in the 1950s and now», Daedalus (verano): 143-162.

Wallwork, E. (1972): Durkheim: Morality and Milieu, Cambridge, Massachusetts: Harvard University Press.

Wander, Ph. C. (1976): «The rhetoric of science», Western Speech Communication, 40: 226235.

Weber, M. (1958): The Protestant Ethic and the Spirit of Capitalism, Nueva York: Charles Scribner.

Weigert, A. (1970): «The immoral rhetoric of scientific sociology», The American Sociologist, 5: 111-119.

Weimer, W. B. (1977): «Science as a rhetorical transaction: toward a non-justificational conception of rhetoric", Philosophy and Rhetoric, 10: 1-29.

Zelditch, M. (1979): «Comment», The American Sociologist, 14: 52-55.

(Traducción: Amparo LASÉN DíAZ.) 


\begin{abstract}
To ilustrate rhetorical approaches to texts in the social sciences, this essay takes Durkheim's Suicide, commonly thought to be a positivist exemplar, and reads it as moral discourse. The first part suggests the illumination given to the patterns of argumentation when the volume is treated as a response to a contemporary situation that could be shaped by persuasive discourse. The latter part presents the classic status of the volume as resultung from its use as a rhetorical authority to license some kinds of sociology.
\end{abstract}

